\title{
Comparative study of filler influence on polylactide photooxidation
}

\author{
S. Bocchini ${ }^{1 *}$, A. Frache ${ }^{2}$ \\ ${ }^{1}$ Center for Space Human Robotics@PoliTo, Istituto Italiano di Tecnologia, C.so Trento 2110129 Turin, Italy \\ ${ }^{2}$ Dipartimento di Scienza Applicata e Tecnologia, Politecnico di Torino sede di Alessandria, Viale Teresa Michel 5, \\ 15121 Alessandria, Italy
}

Received 17 November 2012; accepted in revised form 26 January 2013

\begin{abstract}
Polylactide (PLA) based nanocomposites of organically modified montmorillonite and micro-talc based microcomposites were prepared with different compositions and were UV-light irradiated under artificial accelerated conditions representative of solar irradiation. The chemical modifications resulting from photo-oxidation were followed by infrared (IR) and ultraviolet (UV)-visible spectroscopies. The infrared analysis of PLA photooxidation shows the formation of a band at $1847 \mathrm{~cm}^{-1}$ due to the formation of anhydrides. The filler addition provokes an increase of anhydride formation rate dependent on filler nature, amount and dispersion degree on the matrix. The main factors that influence oxidation rate are the total extension of polymer/filler interfacial area and the presence of transition metal impurities of clays.
\end{abstract}

Keywords: nanocomposites, polylactide, photooxidation, biopolymers

\section{Introduction}

In the market of biodegradable polymers, polylactide (PLA) is undoubtedly one of the most promising candidates for further developments as it is not only biodegradable but also produced from renewable resources, such as sugar beet and corn starch. Due to its attractiveness, PLA is currently receiving considerable attention for conventional applications such as packaging, textile fibres and more recently, as (nano)composites for technical applications. Unfortunately the range of application of PLA is severely limited because of low glass transition temperature (around $55-60^{\circ} \mathrm{C}$ ) thus in response to the demand for extending the range of PLA applications the main route to increase mechanical and thermomechanical properties of PLA was the preparation of PLA-based nanocomposites [1-5] achieving remarkable improvements of the polymer properties observed even at nanofiller content as low as
$3-5 \mathrm{wt} \%$ without the loss of biodegradability $[6,7]$, or the addition of a nucleating/reinforcing agent such as talc [8] or calcium sulphate anhydrite [9, $10]$.

The resistance to ultraviolet (UV) light is a key factor for most outdoor applications of polymeric materials. In the last few years, the impact of light on polymer/clay nanocomposites has been studied [11-19]. The clay nanocomposites show a significant reduction of the oxidation induction time (OIT). In a previous series of papers concerning the photooxidation of montmorillonite/polypropylene [13-15] several hypotheses have been proposed to explain the oxidative degradation of these materials. The reduction of the OIT could result from the adsorption of antioxidants onto the nanofiller, and/or a catalytic effect of transition metal impurities of nanofillers, and also from additional initiation routes due to the oxidation of the organic modifiers in the

\footnotetext{
*Corresponding author, e-mail: sergio.bocchini@iit.it

(C) BME-PT
} 
nanofillers. The most probable hypothesis was the presence of interactions between the nanofillers and the stabilizers: the antioxidants can be adsorbed on the nanofillers thus preventing their protective action [13-18]. In a previous article the photo-oxidation mechanism of PLA [19] was investigated. The proposed mechanism was the formation of anhydride functional groups by a radical peroxide mechanism (Figure 1). In the presence of moisture the successive anhydride hydrolysis promotes degradation of polylactide. These findings were confirmed by Gardette et al. [20]. In the same article they also explain that under the conditions typical of outdoor exposure other reaction such as Norrish II are improbable.

The photooxidation of PLA-nanocomposites with different types of nanoparticles was also studied [19]. As a general statement the nanoparticle addition does not change the mechanism but, on the basis of the nanoparticle type, an increase of anhydride formation was noted. The main factor responsible for this acceleration was identified in the presence of transition metal ions contained in the nanofillers as impurities and involved in the cat- alytic hydroperoxide decomposition. The main effect of the eventual clay organic modifiers is instead the increase of initial dispersion of the nanofillers with a consequent increased interaction between nanofiller and PLA.

The aim of the present work is to study the effect of clay nanoparticles concentration on the photooxidation behaviour of PLA, moreover a comparison with a micrometric traditional filler such as talc often used in combination with PLA because of its nucleation properties $[8,21]$, and that already provoked an increase in photooxidation in polyonlefin/talc composites [22, 23], was made.

\section{Experimental}

\subsection{Materials}

Poly(L-lactic acid) 'NatureWorks ${ }^{\circledR}$ PLA Polymer 3051D', average molecular weight $160 \mathrm{kDa}$, ratio 96\% L-Lactide to 4\% D-Lactide units was purchased from Natureworks Minneapolis Minnesota (USA). Industrial microtalc masterbatch 'PLA NA BIO L 6951' with a composition of $30 \mathrm{wt} \%$ of microsized talc content based and $70 \mathrm{wt} \%$ of 'NatureWorks ${ }^{\circledR}$ PLA Polymer 3051D' was purchased from
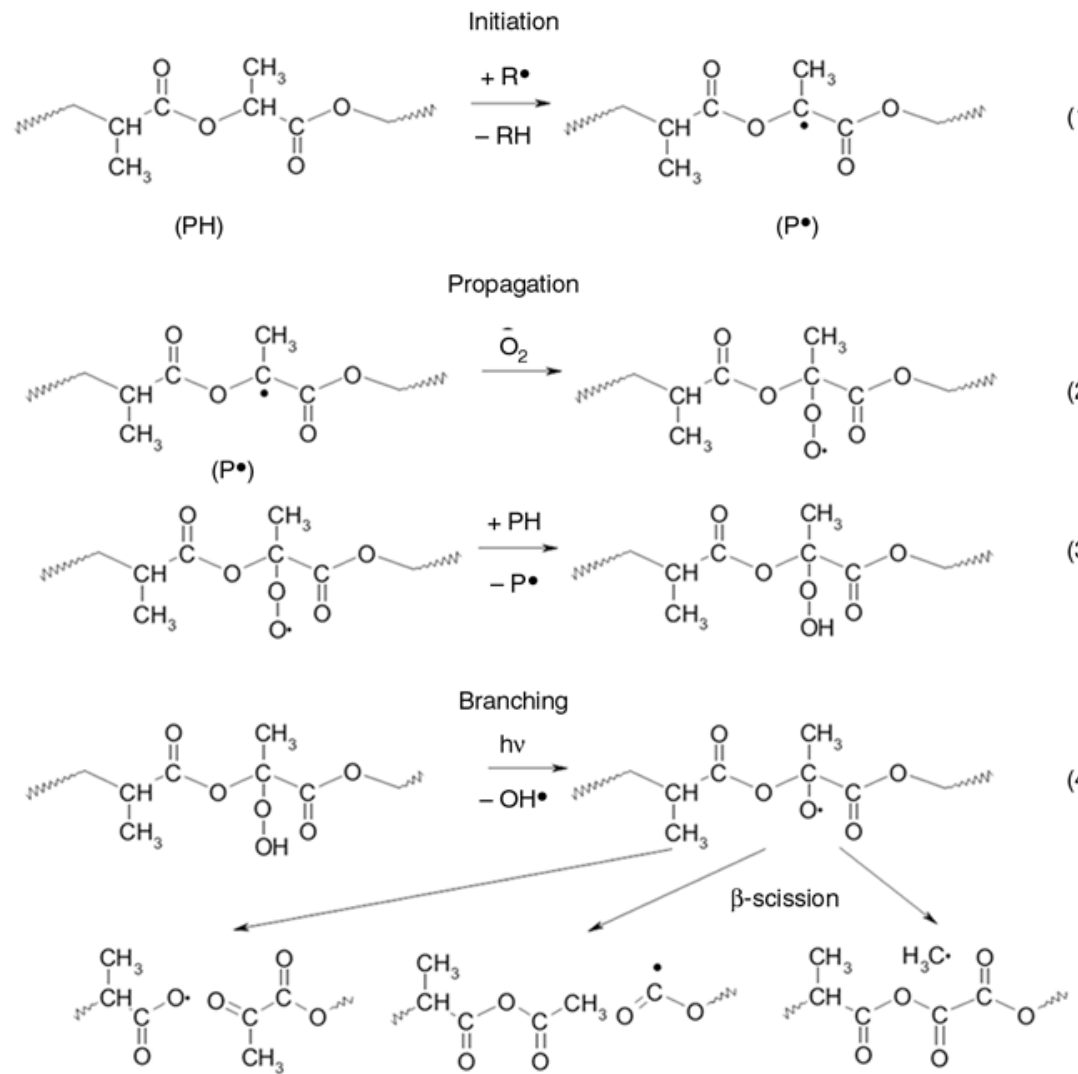

(5a)

(5c)

Figure 1. Radical oxidation process of irradiated PLA samples: hydroperoxide chain propagation and formation of anhydrides by photolysis of hydroperoxide [19] (Reproduced with permission) 
Table 1. Characteristics of particles/nanoparticles used

\begin{tabular}{|c|c|c|c|}
\hline Commercial name & Cloisite $^{\circledR}$ 30B & Cloisite $^{\circledR}$ 20A & NA BIO L6951 \\
\hline Type of nanoparticles & \multicolumn{2}{|c|}{ Montmorillonite } & Talc \\
\hline Chemical formula & {$\left[\mathrm{Al}_{3.34} \mathrm{Mg}_{0.66}\right]\left(\mathrm{Si}_{8} \mathrm{O}_{20}\right)(\mathrm{OH})_{4}^{-0.66}$} & $\mathrm{Mg}_{3} \mathrm{Si}_{4} \mathrm{O}_{10}(\mathrm{OH})_{2}$ & \\
\hline \multirow[t]{2}{*}{$\begin{array}{l}\text { Organic modifier type } \\
{[\mathrm{wt} \%]}\end{array}$} & & & None \\
\hline & \multicolumn{2}{|l|}{$\mathrm{OH}$} & - \\
\hline Platelet length $[\mu \mathrm{m}]$ & \multicolumn{2}{|c|}{$0.5^{\mathrm{b})}$} & $2-10^{\mathrm{c})}$ \\
\hline \multicolumn{4}{|l|}{$\mathrm{EDS}^{\mathrm{d})}$} \\
\hline $\mathrm{Si}[\mathrm{wt} \%]$ & $26.0 \pm 1.8$ & $25.5 \pm 2.5$ & $29.9 \pm 1.7$ \\
\hline $\mathrm{Al}[\mathrm{wt} \%]$ & $10.1 \pm 0.4$ & $9.2 \pm 0.8$ & $18.5 \pm 0.3$ \\
\hline $\mathrm{O}[\mathrm{wt} \%]$ & $59.5 \pm 2.7$ & $61.2 \pm 3.8$ & $51.6 \pm 1.7$ \\
\hline $\mathrm{Mg}[\mathrm{wt} \%]$ & $1.1 \pm 0.1$ & $1.3 \pm 0.2$ & - \\
\hline $\mathrm{Fe}[\mathrm{wt} \%]$ & $3.1 \pm 1.1$ & $2.3 \pm 0.4$ & - \\
\hline $\mathrm{Na}[\mathrm{wt} \%]$ & $0.1 \pm 0.1$ & $0.5 \pm 0.2$ & - \\
\hline Code & $\mathrm{Cl} 30 \mathrm{~B}$ & $\mathrm{Cl} 20 \mathrm{~A}$ & $\mathrm{~T}$ \\
\hline
\end{tabular}

HT - hydrogenated linear alkyl chains: C $8 \sim 18$

a) $\mathrm{Wt} \%$ obtained by calcination at $800^{\circ} \mathrm{C}$

b) On the basis of estimation from sodium montmorillonite precursor [24]

c) Estimated from SEM analyses (Figure 4)

d) Qualitative elemental analysis of by energy dispersive X-ray spectroscopy (EDS) wt\% on the basis of the inorganic part (excluding organic modifiers)

Polyone Belgium SA Assesse (Belgium). Two different commercial nanoclays (Southern Clay Products, Inc.), Cloisite ${ }^{\circledR}$ 30B (Cl30B), sodium montmorillonite modified with bis-(2-hydroxyethyl) methyl tallow alkyl ammonium cations and Cloisite ${ }^{\mathbb{R}} 20 \mathrm{~A}$ (C120A), sodium montmorillonite modified with dimethyl, dehydrogenated tallow, quaternary ammonium cations were used. The characteristics of the particles used in this work are listed in Table 1.

Prior to melt blending, PLA and talc masterbatch were dried at $80^{\circ} \mathrm{C}$ under vacuum until residual moisture measured by Karl Fisher was lower than $190 \mathrm{ppm}$. Similarly clays were dried at $100^{\circ} \mathrm{C}$ under vacuum until moisture lower than 400 ppm measured by Karl Fisher was achieved.

\subsection{Materials processing}

The composites were prepared via melt-processing using a Leistritz co-rotating twin screw extruder $(d=18 \mathrm{~mm}, l / d=40)$. The flow was $4.0 \mathrm{~kg} / \mathrm{h}$, and the rotation speed was $150 \mathrm{rpm}$. The residence time was about $50 \mathrm{~s}$. The screw configuration with the temperature profile from the feeding zone to the die, previously optimized to obtain the best filler dispersion inside PLA, is reported in Table 2.

The samples were prepared by direct addition of the different nanofiller and masterbatch in the feeding zone. The compositions are listed in Table 3. The code PLAXX gives the filler content expressed as $\mathrm{XX} w \mathrm{w} \%$.

$30 \times 30 \times 1 \mathrm{~mm}^{3}$ samples for wide angle X-ray analyses were prepared using a hot-plate hydraulic press at $190^{\circ} \mathrm{C}$. A pressure of 100 bar was applied for 1 minute and thus the samples were cooled at $10{ }^{\circ} \mathrm{C} \min ^{-1}$.

Film samples for photooxidation were prepared from pellets using a hot-plate hydraulic press at $190{ }^{\circ} \mathrm{C}$ using a pressure of 100 bar for 1 minute and rapidly cooled to room temperature to avoid oxidation/degradation and PLA crystallization, in order to have oxygen saturation during film photo-oxidation the film thickness was kept under 15-20 $\mu \mathrm{m}$.

\subsection{Materials photooxidation process}

Irradiations of specimens at $\lambda>300 \mathrm{~nm}$ were carried out in air in a SEPAP $12 / 24$ unit at $45^{\circ} \mathrm{C}$. This apparatus is equipped with four medium-pressure mercury lamps with borosilicate envelope which filters wavelengths below $300 \mathrm{~nm}$ and it is designed for the study of polymer photodegradation in artificial conditions that are relevant to natural outdoor weathering [25].

\subsection{Characterization}

Wide angle X-ray diffractograms (WAXS) were recorded at room temperature in the range $1-30^{\circ}$ 
Table 2. Description of screw and temperature profiles from the feeding zone to the die

\begin{tabular}{|c|c|c|c|c|}
\hline Element $^{\text {a) }}$ & Type $^{\text {b) }}$ & Number of element & Length & $\begin{array}{c}\text { Temperature } \\
{\left[{ }^{\circ} \mathbf{C}\right]}\end{array}$ \\
\hline GFF 2-30-90 & Conveying & 1 & 90 & Cooled \\
\hline GFA 2-30-30 & Conveying & 2 & 60 & 195 \\
\hline KB4 2-15-30 RE & Kneading & 2 & 30 & 195 \\
\hline KB4 2-15-60 RE & Kneading & 2 & 30 & 192 \\
\hline KB4 2-15-90 RE & Kneading & 2 & 30 & 192 \\
\hline GFA 2-30-60 & Conveying & 1 & 60 & 192 \\
\hline GFA 2-30-30 & Conveying & 1 & 30 & 190 \\
\hline GFA 2-20-30 & Conveying & 1 & 30 & 190 \\
\hline KB4 2-15-30 RE & Kneading & 1 & 15 & 190 \\
\hline KB4 2-15-60 RE & Kneading & 1 & 15 & 190 \\
\hline KB4 2-15-90 RE & Kneading & 1 & 15 & 185 \\
\hline GFA 2-30-30 & Conveying & 1 & 30 & 185 \\
\hline GFA 2-15-15 LI & Kneading & 1 & 15 & 185 \\
\hline GFA 2-20-30 & Conveying & 2 & 60 & 180 \\
\hline KB4 2-15-30 RE & Kneading & 1 & 15 & 180 \\
\hline KB4 2-15-60 RE & Kneading & 2 & 30 & 180 \\
\hline KB4 2-15-90 RE & Kneading & 1 & 15 & 175 \\
\hline GFA 2-30-60 & Conveying & 1 & 60 & 175 \\
\hline GFA 2-20-60 & Conveying & 1 & 60 & 170 \\
\hline GFA 2-15-30 & Conveying & 1 & 30 & 165 \\
\hline
\end{tabular}

a)the letters stand for $\mathrm{G}$ - corotating; F (in the second position) - conveying; A - free-meshing; F (in the third position) - freely cut; KB kneading block; RE - conveying. LI - counterflow

b) Conveying block: the three numbers indicate the thread length, the pitch length, and the screw element respectively; kneading block: the three numbers stand for the kneading block, the thread number, the length of the kneading block, and the twisting angle of the kneading segments.

Table 3. Composition of melt-blended samples

\begin{tabular}{|l|c|c|}
\hline \multicolumn{1}{|c|}{ Samples name } & $\begin{array}{c}\text { Cloisite } \\
{[\mathbf{w t} \% \mathbf{l} \text { (Type) }}\end{array}$ & $\begin{array}{c}\text { Masterbatch } \\
{[\mathbf{w t} \% \mathbf{l} \text { of talc }}\end{array}$ \\
\hline PLA & - & - \\
\hline PLA2.5Cl20A & $2.5(\mathrm{Cl} 20 \mathrm{~A})$ & - \\
\hline PLA5Cl20A & $5.0(\mathrm{Cl20A})$ & - \\
\hline PLA2.5Cl30B & $2.5(\mathrm{Cl} 30 \mathrm{~B})$ & - \\
\hline PLA5Cl30B & $5.0(\mathrm{Cl} 30 \mathrm{~B})$ & - \\
\hline PLA5T & - & 5.0 \\
\hline PLA10T & - & 10.0 \\
\hline
\end{tabular}

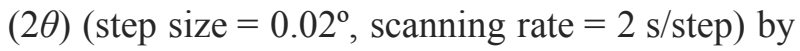
using filtered $\mathrm{Cu} \mathrm{K}_{\alpha}$ radiation $(\lambda=1.54 \AA)$ with a Thermo ARL diffractometer X-tra 48.

Specimens for Transmission Electron Microscopy (TEM) characterizations were microtomed at $-196^{\circ} \mathrm{C}$ with an Ultramicrotome Leica UCT to obtained thickness about $90 \mathrm{~nm}$. The grid was 50 meshes, coated with SPI-Chem ${ }^{\mathrm{TM}}$ Pioloform ${ }^{\circledR} \mathrm{B}$ Resin. The analyses were performed with a Philips CM 120 microscope.

Scanning Electron Microscopy (SEM) was carried out on the cryogenic fracture surfaces of the $0.6 \mathrm{~mm}$ specimens previously coated by sputtering with gold, using a Leo 14050 VP SEM apparatus. Energy dispersive X-ray spectroscopy (EDS) was performed on the original $\mathrm{Cl} 20 \mathrm{~A}$ and $\mathrm{Cl} 30 \mathrm{~B}$ and on microtalc

obtained by calcination of PLA NA BIO L 6951. The results were the statistic of 12 different sampling.

Infrared spectra (FT-IR) of films were recorded with a Perkin-Elmer Spectrum GX Infrared Spectrometer. Spectra were obtained using 16 scans and a $4 \mathrm{~cm}^{-1}$ resolution.

Photooxidation of PLA was followed by the intensity of the $1847 \mathrm{~cm}^{-1}$ peak $v_{\mathrm{C}=\mathrm{O}}$ of anhydride, which was plotted as a function of time; to avoid differences due to film thickness, it was normalized using the infrared (IR) absorption band at $2997 \mathrm{~cm}^{-1} v_{\mathrm{C}-\mathrm{H}}$ (asymmetric $v_{\left(\mathrm{CH}_{3}\right)}$ band of PLA).

UV-visible spectra (UVvis) of films were recorded on a Shimadzu UV-2101 PC spectrometer equipped with an integrating sphere.

\section{Results and discussions}

\subsection{Morphology}

WAXS is one of the methods used to assess the dispersion of clay in a polymeric matrix. From the position of the first peak in the diffractogram the distance $d_{001}$, commonly named 'interlayer-spacing', is calculated using the Bragg's law. The WAXS analyses of PLA-nanocomposites used in this work 
were already reported in a previous work [26], thus for the sake of brevity only a resume of the results is reported. The $d_{001}$ for $\mathrm{Cl} 20 \mathrm{~A}, \mathrm{Cl} 30 \mathrm{~B}$ and the respective PLA nanocomposites are reported in Table 4. $\mathrm{Cl} 20 \mathrm{~A}$ is characterized by a first diffraction peak at $2 \theta=3.5^{\circ}[19]$ corresponding to an interlayer distance $\left(d_{001}\right)$ related to the presence of the organic modifier molecules between clay layers and accounting for a $d_{001}=2.5 \mathrm{~nm}$. When $\mathrm{Cl} 20 \mathrm{~A}$ is blended in PLA a shift of this peak to lower angles is observed, corresponding to the increase of the $\mathrm{Cl} 20 \mathrm{~A}$ interlayer distance to $3.5 \mathrm{~nm}$, indicating the formation of an intercalated structure. In the case of PLAC130B the $d_{001}$ peak shifts from the original value of $2 \theta=4.7^{\circ}(1.8 \mathrm{~nm})$ of $\mathrm{Cl} 30 \mathrm{~B}$ to $2 \theta=2.4^{\circ}$ $(3.6 \mathrm{~nm})$ showing that also in this case an intercalated structure is achieved. Moreover, there is no sensible effect of clay concentration on X-rays diffractograms either in the case of $\mathrm{Cl} 20 \mathrm{~A}$ or in that of $\mathrm{Cl} 30 \mathrm{~B}$ in the range of concentration of Table 3. As expected there are no traces of PLA crystalline structure both for PLA (Figure 2) and for PLA nanocomposites based on clay nanoparticles, as already reported in literature for PLA/organically modified montmorillonite nanocomposites [19, 26-28]. These observations are in perfect agreement with the previously published data $[5,19,27-29]$ on similar materials.

The WAXS pattern of PLA is characterized by a broad band with maximum at $2 \theta \approx 17^{\circ}$, indicating a completely amorphous structure (Figure 2). The WAXS diffractogram of talc is characterized by the presence of three diffraction peaks in the range $2 \theta$ $1-30$, at $2 \theta=9.5,19.1$ and $28.7^{\circ}$ [30]. Crystalline structure of the polymer matrix is significantly affected by the presence of talc: the composites containing talc show the presence of the three talc peaks and a new peak at $16.6^{\circ}$ due to the crystalline phase of the PLA (inset Figure 2) [31]. Thus, as expected talc enhances PLA crystallization, a detailed analysis of the effect of talc on PLA was previously reported by our group [8], in the case of samples

Table 4. $d_{001}$ interlayer distance for clay and nanocomposites

\begin{tabular}{|l|c|c|}
\hline \multirow{2}{*}{ Sample name } & \multicolumn{2}{|c|}{ Interlayer distance [nm] } \\
\cline { 2 - 3 } & Clay & Nanocomposite \\
\hline PLA2.5Cl20A & $2.5 \pm 0.05$ & $3.5 \pm 0.05$ \\
\hline PLA5Cl20A & $2.5 \pm 0.05$ & $3.5 \pm 0.05$ \\
\hline PLA2.5Cl30B & $1.7 \pm 0.05$ & $3.6 \pm 0.05$ \\
\hline PLA5C130B & $1.7 \pm 0.05$ & $3.6 \pm 0.05$ \\
\hline
\end{tabular}

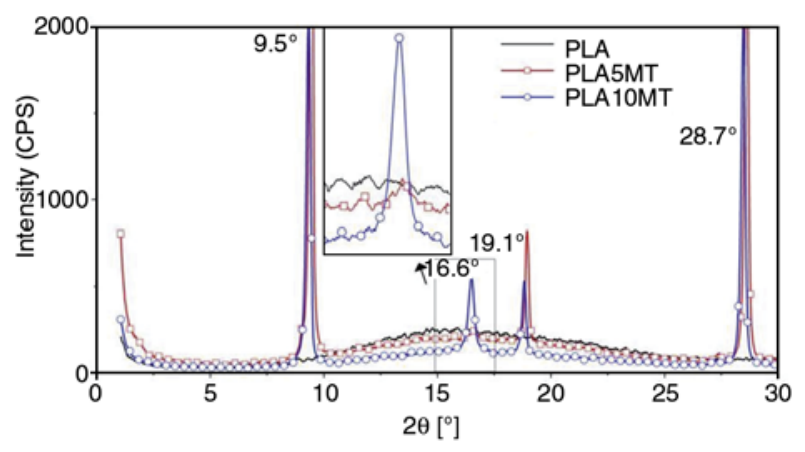

Figure 2. X-ray diffraction of melt-blended samples (inset: magnification of PLA characteristic peak)

prepared with similar cooling rate $\left(10^{\circ} \mathrm{C} \mathrm{min}^{-1}\right)$ the crystalline content seems to be proportional to talc content even if taking into account the thickness of the sample $(1 \mathrm{~mm})$ and the inaccurate coolingmethod (the water cooling of hydraulic press) these measures should be considered only qualitatively and with low precision.

PLA based nanocomposites were further analysed by means of TEM (Figure 3). The incorporation of Cl20A in the PLA matrix (Figure 3a-3d) shows certain level of intercalation as well as the occurrence of exfoliated silicate layers. When correlating these observations with X-ray diffraction (XRD) results, we can conclude that the C120A forms partially exfoliated nanocomposites. PLA nanocomposites based on C130B show a high level of intercalation and exfoliation of the silicate layers (Figure 3e-3h), as small stacks of swollen clay layers and single dispersed layers can be observed in the TEM micrograph, results that are in accordance with WAXS analyses.

In the case of talc-PLA composites taking into account the expected formation of micrometric composites SEM analyses was preferentially performed (Figure 4a). In the two composites (PLA5T and PLA10T) talc particles show a good dispersion at micrometric level (Figure 4).

From WAXS and TEM results, it is clear that the dispersion and interaction of the C130B in PLA is better than that obtained with Cl20A.

From Table 1, XRD and TEM data the following conclusions can be achieved: the dispersion of $\mathrm{Cl} 30 \mathrm{~B}$ is higher than the dispersion of $\mathrm{Cl} 20 \mathrm{~A}$ in the different nanocomposites thus the total interfacial area polymer/nanofiller is higher for the nanocomposites containing $\mathrm{Cl} 30 \mathrm{~B}$ than for the nanocomposites containing C120A. Taking into account the thickness of few nanometres for the $\mathrm{Cl} 20 \mathrm{~A}$ and $\mathrm{Cl} 30 \mathrm{~B}$ platelets 


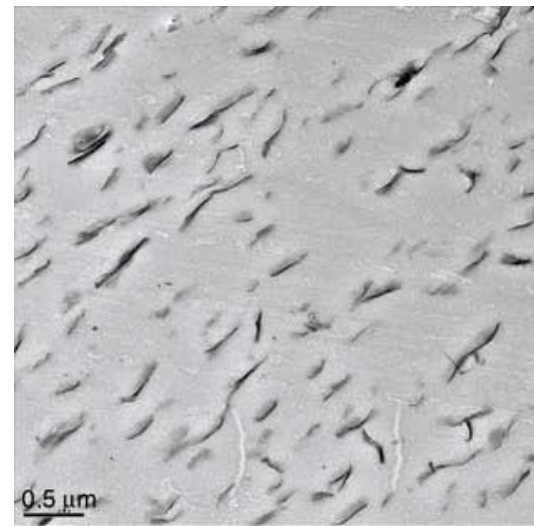

a)

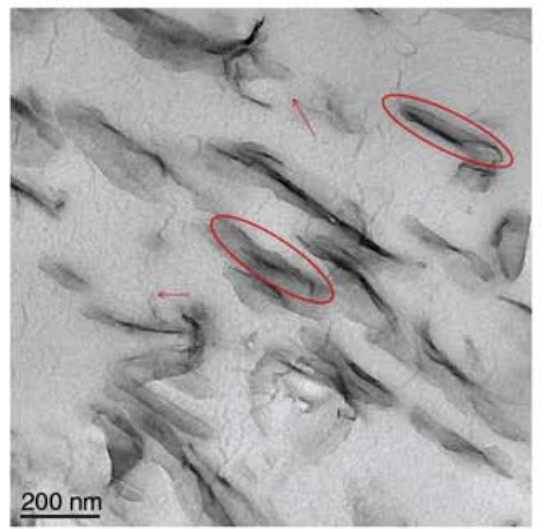

d)

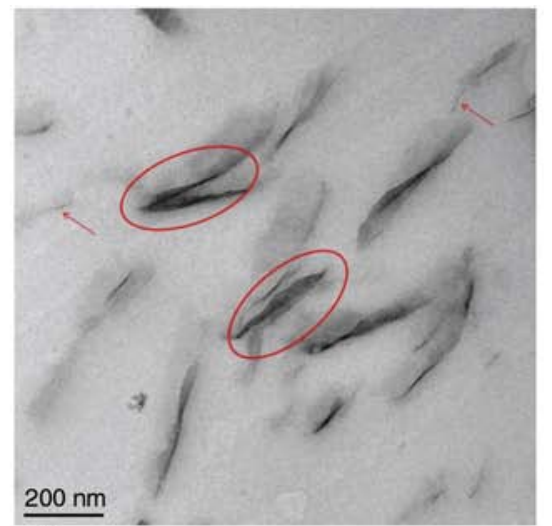

b)

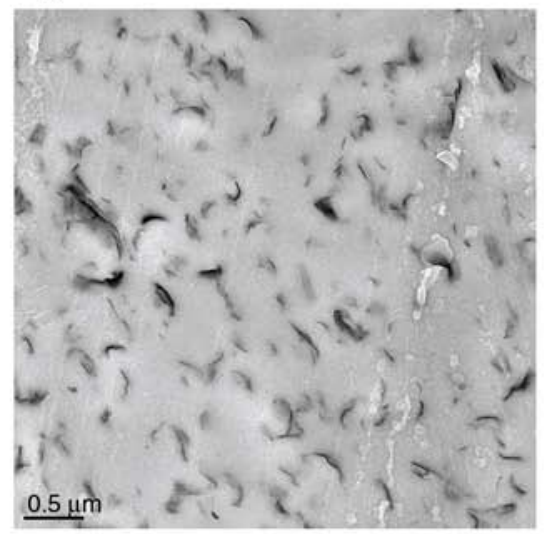

e)

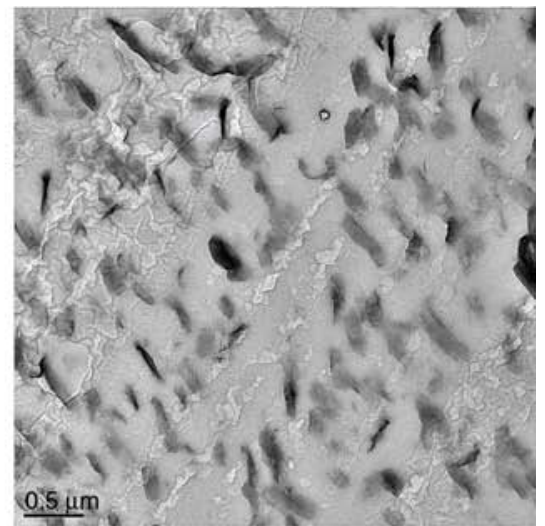

c)

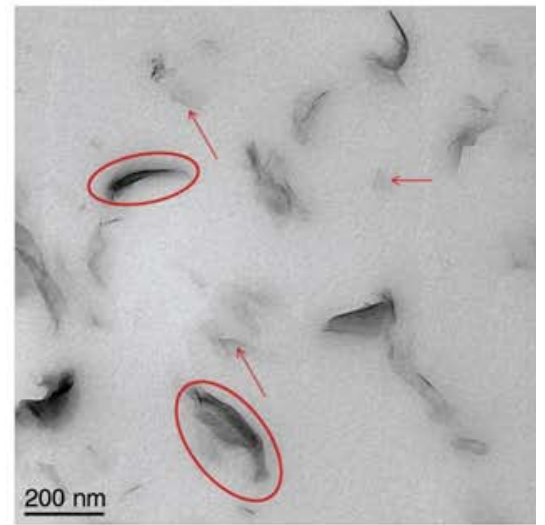

f)

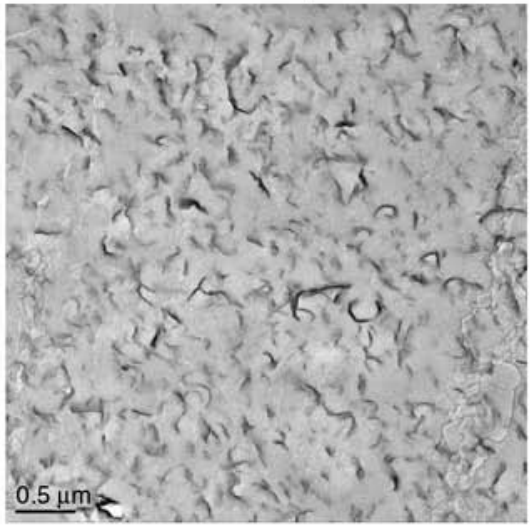

g)

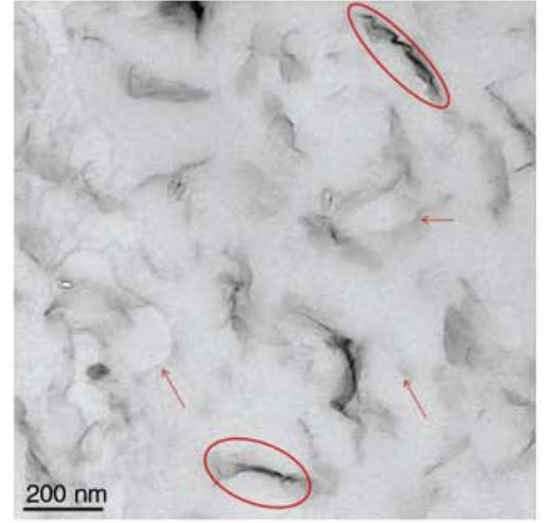

h)

Figure 3. TEM micrographs of nanocomposites, example of exfoliated lamellae are indicated by arrows, example of intercalated lamellae are encircled a), b) PLA2.5Cl20A, c), d) PLA5Cl20A e), f) PLA2.5Cl30B, g), h) PLA5Cl30B

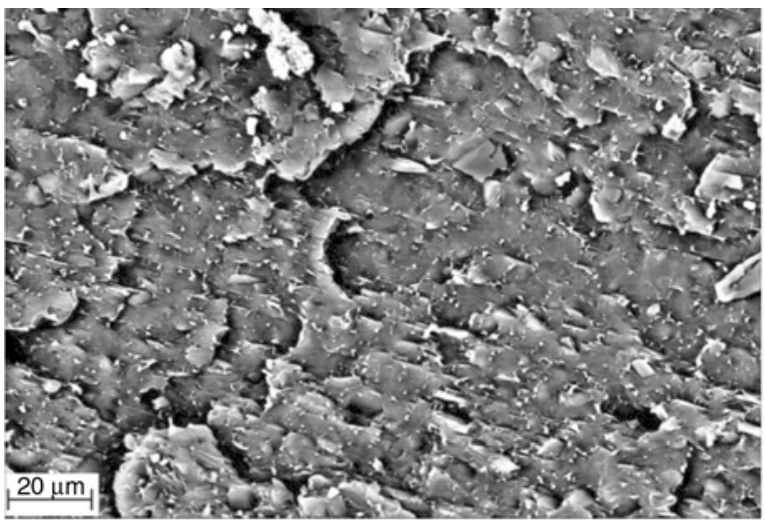

a)

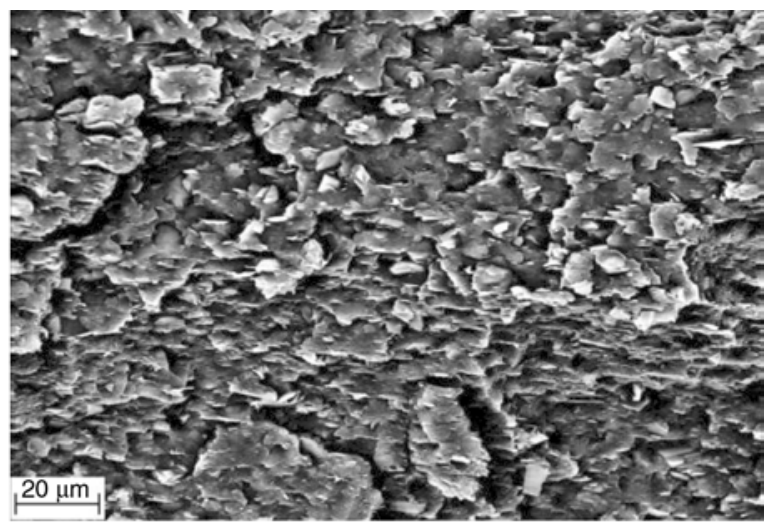

b)

Figure 4. Scanning electron micrographs on cryogenic fractured, gold coated surfaces for (a) PLA5T (b) PLA10T 
and the thickness of talc lamellar, of 2-3 orders of magnitude higher, the interfacial areas of $\mathrm{Cl} 20 \mathrm{~A}$ and $\mathrm{Cl} 30 \mathrm{~B}$ nanocomposites are of some order of magnitude higher respect to PLA/Talc microcomposites.

\subsection{UV-vis characterization}

Figure 5a shows the UV-vis spectra of pure PLA and nanocomposites. For PLA there is a saturation of the spectra below about $230 \mathrm{~nm}$ due to the absorbance of PLA ester groups whereas the nanocomposites show also an absorbance between 230 $300 \mathrm{~nm}$ that is assigned to a $\mathrm{O}^{2-}$ octahedral $\mathrm{Fe}^{3+}$ charge transfer in the montmorillonite structure [32] and was reported for other montmorillonitebased nanocomposites such as polyvinylalcohol sodium montmorillonite nanocomposites [33, 34]. The PLA-talc composites (Figure 5b) do not have absorption bands specific for talc in the UV-vis region however in the whole visible region the light-scattering by the filler particles, proportional to the talc concentration, was found as expected for composite containing micrometric-size filler. The absorbances in the UV-vis region over $300 \mathrm{~nm}$ are quite low and similar for all the samples. Discrepancies in the temperature of samples caused by different absorbance during the photooxidation test can be thus excluded.

\subsection{Infrared characterization}

The peak assignments for neat PLA and the different nanocomposites are shown in Table 5. These assignments are based on values provided in the literature [35].

The IR spectrum of the different nanocomposites (Figure 6) corresponds to those expected from melt blending of the nanofillers with PLA. The main absorbance bands of nanofillers are covered by the saturation of the PLA bands, for the sake of brevity

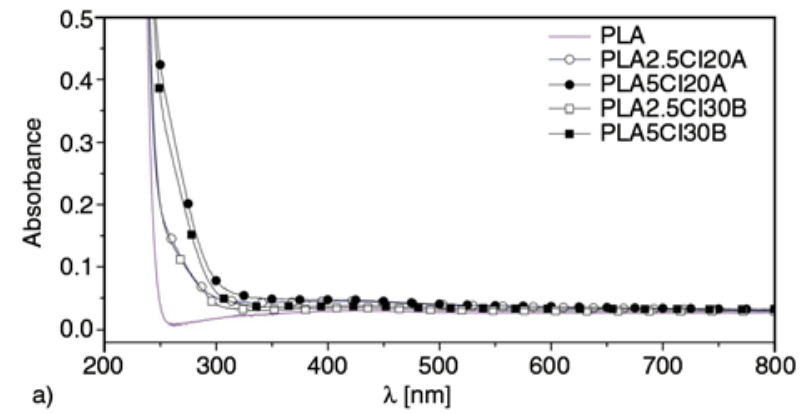

Table 5. Band Assignments of PLA $\left[\mathrm{cm}^{-1}\right]$ [35]

\begin{tabular}{|l|c|c|c|}
\hline \multicolumn{1}{|c|}{ Assignment } & \multicolumn{3}{|c|}{ Assignment } \\
\hline$v_{\mathrm{as}} \mathrm{CH}_{3}$ & 2997 & $\delta \mathrm{CH}+v \mathrm{COC}$ & 1265 \\
\hline$v_{\mathrm{s}} \mathrm{CH}_{3}$ & 2945 & $v_{\mathrm{as}} \mathrm{COC}_{\mathrm{as}} \mathrm{CH}_{3}$ & $1209-1186$ \\
\hline$\nu \mathrm{CH}$ & 2881 & $\mathrm{r}_{\mathrm{as}} \mathrm{CH}_{3}$ & 1132 \\
\hline$\nu \mathrm{CO}$ & 1759 & $v_{\mathrm{s}} \mathrm{COC}$ & 1090 \\
\hline$\delta_{\mathrm{as}} \mathrm{CH}_{3}$ & 1454 & $v_{\mathrm{s}} \mathrm{C}-\mathrm{CH}_{3}$ & 1046 \\
\hline$\delta_{\mathrm{s}} \mathrm{CH}_{3}$ & $1348-1384$ & $\mathrm{rCH}_{3}+v \mathrm{CC}$ & $960-925$ \\
\hline$\delta_{1} \mathrm{CH}+\delta_{\mathrm{s}} \mathrm{CH}_{3}$ & $1368-1360$ & $v \mathrm{C}-\mathrm{COO}$ & 870 \\
\hline$\delta_{2} \mathrm{CH}$ & $1315-1300$ & $\delta \mathrm{CO}$ & 756 \\
\hline
\end{tabular}

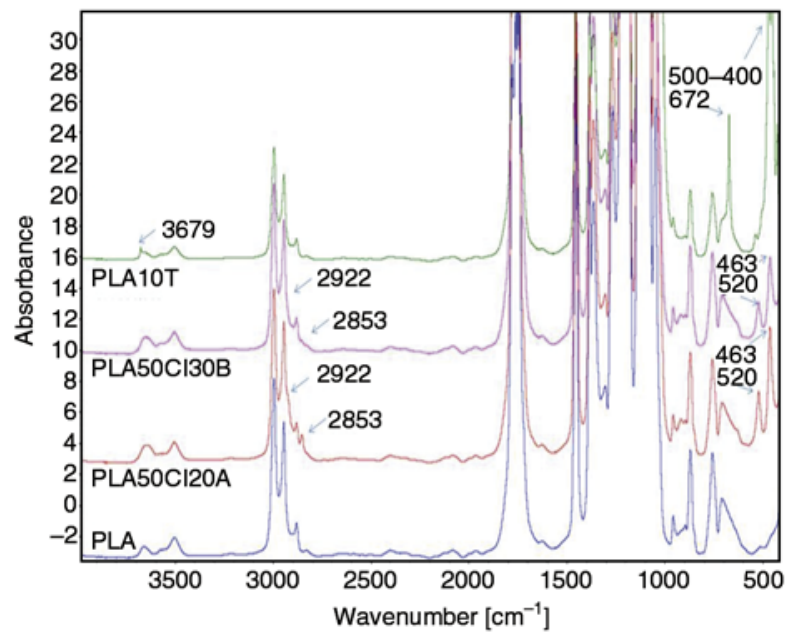

Figure 6. FTIR spectrum of PLA, PLA5Cl20A, PLA5Cl30B and PLA10T

only the spectra of PLA composites with the higher filler concentration are shown, the other samples show the same bands with lower intensity.

In PLA5Cl20A and PLA5C130B the bands that are readily recognizable are 520 and $463 \mathrm{~cm}^{-1}$ that are due to absorbance of the inorganic moieties [36], at the same time it is possible to recognize the $v_{\mathrm{a}} \mathrm{SCH}_{2}$ and $v_{\mathrm{s}} \mathrm{CH}_{2}$ of the organic modifiers respectively at 2924 and $2854 \mathrm{~cm}^{-1}$. In the case of PLA10T the main differences are due to the sharp $v \mathrm{OH}$ of talc at $3679 \mathrm{~cm}^{-1}$ and the libration modes of the $\mathrm{MgOH}$ terminal groups at about $672 \mathrm{~cm}^{-1}$ and between 500 and $400 \mathrm{~cm}^{-1}$ [37]. Both for PLA and PLA micro/

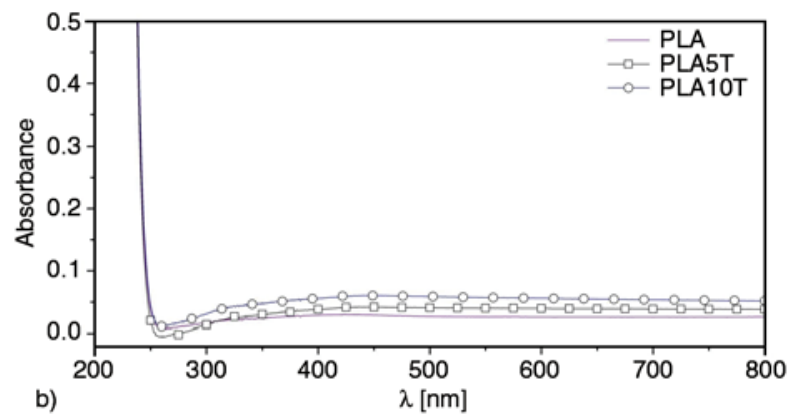

Figure 5. UV spectra a) PLA nanocomposites, b) PLA-talc composites 
nanocomposites peaks that can be referred directly to crystal phase are completely absent [38] confirming that the film samples prepared by rapid cooling contains PLA in the amorphous phase.

\subsection{Samples photo-oxidation}

The reactions that occur to PLA during photooxidation were already discussed in previous articles [19, $20]$ and reported in Figure 1. Photooxidation usually begins by radicals formed from impurities by UV-irradiation or thermal decomposition. The reaction with higher probability is the abstraction of tertiary hydrogen from PLA chain with the formation of a tertiary radical $\mathrm{P} \cdot(1)$.This radical can react with oxygen to form a peroxide radical (2), the reaction propagates by abstraction of another tertiary hydrogen with the formation of an hydroperoxide and the initial radical $P \bullet$ (3). The hydroperoxide could undergoes photolysis (4) with formation of $\mathrm{HO} \cdot$ and a $\mathrm{PO}$ radicals that can further evolve by $\beta$-scission (5). Taking into account the stability of the different fragments the most probable $\beta$-scission is the $(5 b)$ reaction that leads to the formation of an anhydride. The photolysis of the hydroperoxides is responsible for the branching character of polymer photooxidation processes. The results of this mechanism is the formation of a band with a maximum at $1847 \mathrm{~cm}^{-1}$ due to the asymmetric stretching of anhydride groups [39] and an absorption in the hydroxyl region (a broad band in the $4000-3000 \mathrm{~cm}^{-1}$ ) that corresponds to by-products of the photooxidation mechanism such as hydroperoxides and alcohols $[17,18]$. These results were confirmed by photooxidation of PLA (Figure 7a).

The evolution of photooxidation by FTIR spectra of a nanocomposite (PLA5C130B Figure 7b) and a talc composite (PLA5T Figure 7c) vs time are shown. The addition of $\mathrm{Cl} 30 \mathrm{~B}$ does not change the infrared spectra modification; the appearance of the $1847 \mathrm{~cm}^{-1}$ absorption and of a broad band in the 4000$3000 \mathrm{~cm}^{-1}$ region. Similar behaviour was obtained for all nanocomposites. The oxidation rate increases with the nanofiller concentration and it is higher for Cl30B nanocomposites. In the case of PLA/talc microcomposites a similar spectra evolution was found but the increase of the two characteristic bands with time is less pronounced.

The increase of oxidation rate due to addition of nanoclays such as $\mathrm{Cl} 20 \mathrm{~A}$ or $\mathrm{Cl} 30 \mathrm{~B}$ was qualitatively attested in a previous article [19]. It was attrib- uted to the transition metal impurities of clay. However no quantitative assessment of the effect of concentration on oxidation rate was performed. Taking into account the linearity between time and absorbance of the $1847 \mathrm{~cm}^{-1}$ peak, reported also from other groups such as Gardette et al. [20], in this work the oxidation rate was evaluated by linear regression of the normalized absorbance as a function of time (Figure 8, Table 6). From the obtained data it is evident that the oxidation rate of PLA increases linearly with fillers, such as talc, or nanofillers, such as $\mathrm{Cl} 20 \mathrm{~A}$ or $\mathrm{Cl} 30 \mathrm{~B}$ concentrations.

The main differences between the different micro/ nanocomposites are: the presence of organic modifiers, the presence of iron in detectable amount for montmorillonite nanofillers (EDS in Table 1), the filler concentration and the different interfacial area.

As previously reported for nanocomposites containing Cl20A [19], the $\mathrm{CH}_{2}$ stretching bands at 2922 and $2853 \mathrm{~cm}^{-1}$ of the nanocomposites containing $\mathrm{Cl} 20 \mathrm{~A}$ and $\mathrm{Cl} 30 \mathrm{~B}$ and assigned to the organic modifier completely disappear in the first hours of oxidation (Figure 9), evidencing that the organic modifiers are easily photodegraded in the begining of photooxidation. Provided that no evidence of low photostability of alkyl chains in onium salts are reported in literature, the rapid decomposition of the organic modifier accounts for a photodegradation activity of montmorillonite surface, this effect is ascribed to a catalytic effect of montmorillonite, possibly linked to the presence of transition metals in the clay structure. Because of this early disappearance, a chemical influence of organic modifiers in the photoodegradation mechanism could be excluded except eventually as a supplementary source of radicals (reaction (1) Figure 1) in the early stage.

The oxidation rate for PLA-clay nanocomposites is not comparable with the increase due to the pres-

Table 6. Oxidation rate (slope) obtained from normalised absorption at $1847 \mathrm{~cm}^{-1}$ of PLA composites and nanocomposites

\begin{tabular}{|l|c|}
\hline \multicolumn{1}{|c|}{ Sample } & Slope $\cdot \mathbf{1 0}^{-\mathbf{6}}\left[\mathbf{h}^{\mathbf{- 1}}\right]$ \\
\hline PLA & $12.9 \pm 0.7$ \\
\hline PLA5T & $18.8 \pm 0.5$ \\
\hline PLA10T & $22.6 \pm 0.1$ \\
\hline PLA2.5Cl20A & $868.8 \pm 9.2$ \\
\hline PLA5Cl20A & $1800 \pm 29.3$ \\
\hline PLA2.5Cl30B & $1500 \pm 21.9$ \\
\hline PLA5C130B & $3140 \pm 31.5$ \\
\hline
\end{tabular}




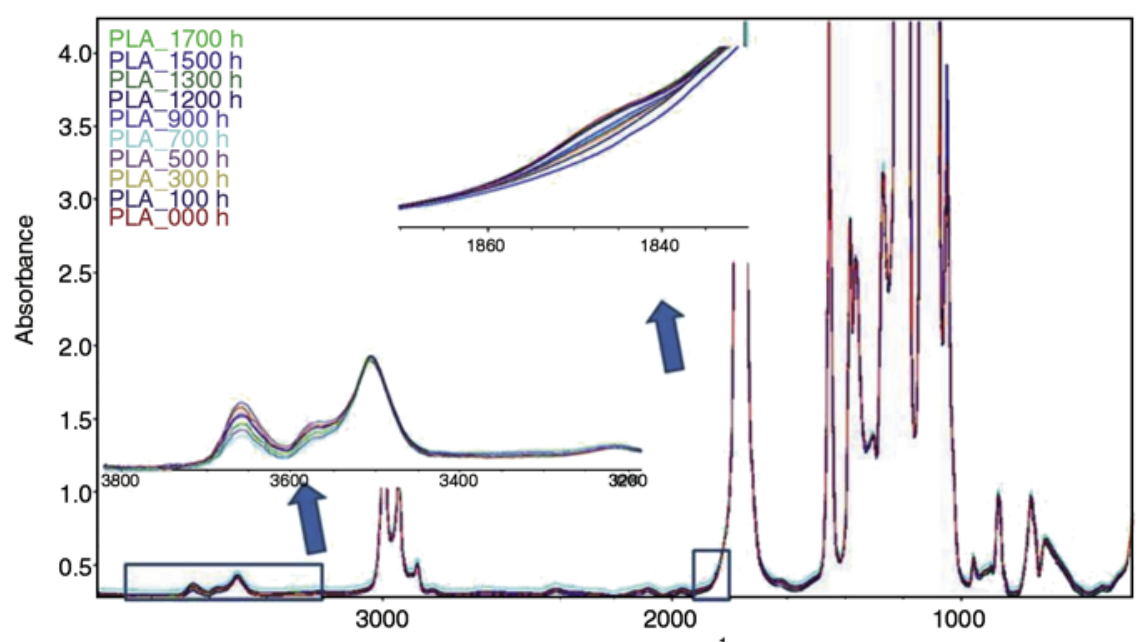

a)

Wavenumbers $\left[\mathrm{cm}^{-1}\right]$

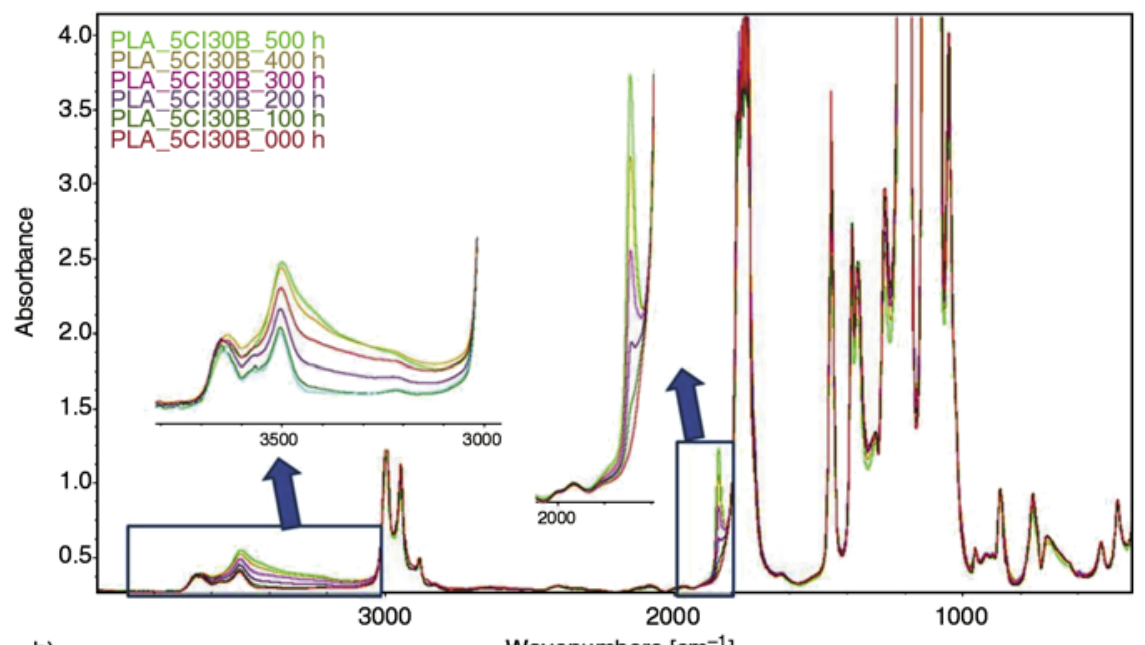

b)

Wavenumbers $\left[\mathrm{cm}^{-1}\right]$

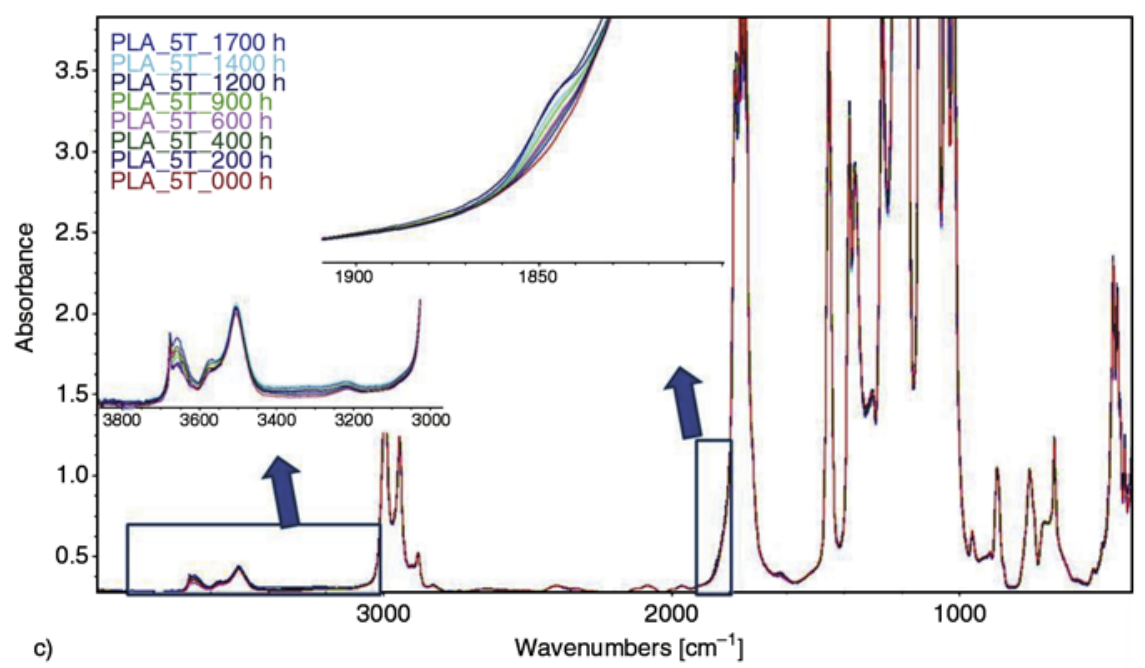

Figure 7. FTIR spectrum vs photooxidation time a) PLA, b) PLA5C130B, c) PLA5T

ence of talc. The oxidation rate for PLA-clay nanocomposites is two orders of magnitude higher (Table 6). The oxidation rate of PLA-clay nanocomposites depends on the type of organic modifier. The C130B nanocomposites, in which there is a better dispersion of the nanofiller, have higher oxi- dation rates. The oxidation rate for both types of clay nanocomposites is directly proportional to clay concentration and thus, taking into account the similar concentration of iron for the two clays (Table 1), the increase of oxidation rate is linked to the increase of interfacial area. In fact interfacial area 

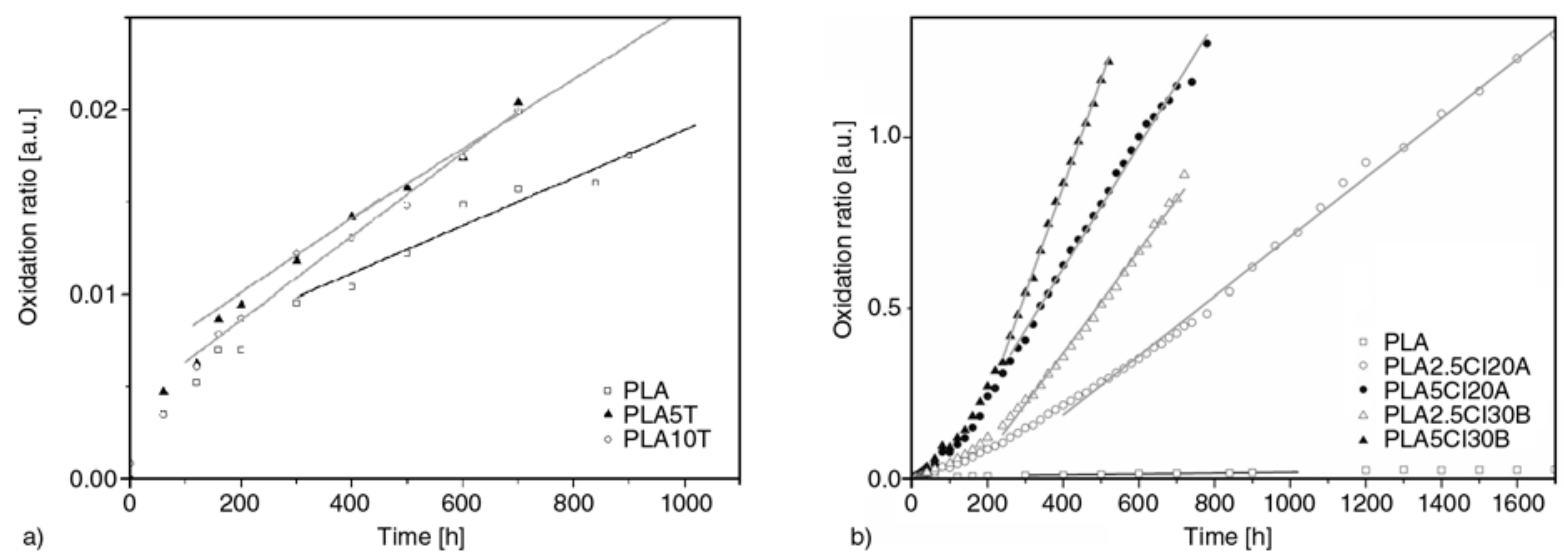

Figure 8. Evolution of $1847 \mathrm{~cm}^{-1}$ anhydride peak vs time a) talc composites b) clay nanocomposites
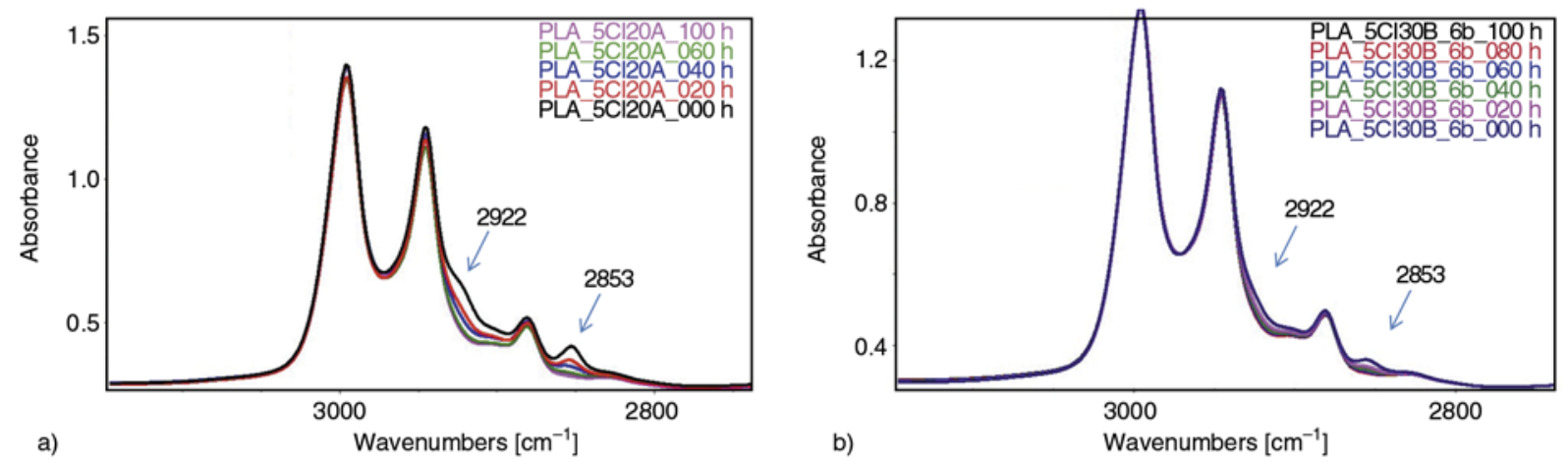

Figure 9. FTIR spectrum ( $v \mathrm{CH}$ zone) vs photooxidation time a) PLA5C120A b) PLA5C130B

increases increasing dispersion degree (e.g. from Cl20A nanocomposites to $\mathrm{Cl} 30 \mathrm{~B}$ nanocomposites as demonstrated in the morphology part) and increasing filler concentration.

The main factor responsible for the increased oxidation rate is the peroxide decomposition in the presence of transition metal impurities. The catalytic effect of metallic compounds has been widely reported and is well-known [40]. Metal ions can cause an acceleration of the oxidation of polymers by various processes including the decomposition of hydroperoxides (Figure 10). The concentration of iron is responsible for the higher oxidation rate for nanocomposites. However a catalytic activity in the peroxide decomposition by Brønsted and Lewis acids groups previously described by Okamoto [41] can be also assumed and could be the responsible for the increase in oxidation rate for the talc micro-

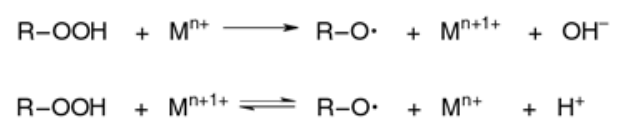

Figure 10. Photocatalytic decomposition of hydroperoxides by transition metal ions: transition metal ion catalyzes the hydroperoxide decomposition composites. All these species can interact better with peroxide by the increase of interfacial area where the polymer is directly in contact with micro/ nanofiller surface.

\section{Conclusions}

The absorbance at $1847 \mathrm{~cm}^{-1}$ is a linear function of irradiation time both for PLA/talc microcomposites and PLA/clay nanocomposites. The addition of filler increases the anhydride formation rate; this increase depends on the size/type of the filler and on iron concentration. Nanoparticles such as clays, with a high interfacial area and a high iron concentration, increase of two orders of magnitude the PLA photooxidation. This increase in the photooxidation rate also depends from the filler concentration and dispersion degree increasing thus with the surface of contact of PLA/nanoclay. On the other end a small effect of the acidic sites on the filler surface cannot be excluded.

\section{Acknowledgements}

The authors would thank Prof Giovanni Camino of Politecnico di Torino (Politecnico di Torino sede di Alessandria) for the feedback and useful comments. 


\section{References}

[1] Jana S. C., Jain S.: Dispersion of nanofillers in high performance polymers using reactive solvents as processing aids. Polymer, 42, 6897-6905 (2001).

DOI: 10.1016/S0032-3861(01)00175-6

[2] Solarski S., Mahjoubi F., Ferreira M., Devaux E., Bachelet P., Bourbigot S., Delobel R., Coszach P., Murariu M., Da Silva Ferreira A., Alexandre M., Degee P., Dubois P.: (Plasticized) polylactide/clay nanocomposite textile: Thermal, mechanical, shrinkage and fire properties. Journal of Materials Science, 42, 51055117 (2007).

DOI: $10.1007 / \mathrm{s} 10853-006-0911-0$

[3] Paul M. A., Alexandre M., Degée P., Henrist C., Rulmont A., Dubois P.: New nanocomposite materials based on plasticized poly(L-lactide) and organo-modified montmorillonites: Thermal and morphological study. Polymer, 44, 443-450 (2003).

DOI: 10.1016/S0032-3861(02)00778-4

[4] Chang J-H., An Y. U., Sur G. S.: Poly(lactic acid) nanocomposites with various organoclays. I. Thermomechanical properties, morphology, and gas permeability. Journal of Polymer Science Part B: Polymer Physics, 41, 94-103 (2003).

DOI: $10.1002 /$ polb.10349

[5] Fukushima K., Tabuani D., Camino G.: Nanocomposites of PLA and PCL based on montmorillonite and sepiolite. Materials Science and Engineering: C, 29, 1433-1441 (2009).

DOI: $10.1016 /$ j.msec.2008.11.005

[6] Ray S. S., Yamada K., Okamoto M., Ueda K.: Control of biodegradability of polylactide via nanocomposite technology. Macromolecular Materials and Engineering, 288, 203-208 (2003).

DOI: $10.1002 /$ mame.200390013

[7] Fukushima K., Tabuani D., Arena M., Gennari M., Camino G.: Effect of clay type and loading on thermal, mechanical properties and biodegradation of poly(lactic acid) nanocomposites. Reactive and Functional Polymers, 73, 540-549 (2013).

DOI: $10.1016 /$ j.reactfunctpolym.2013.01.003

[8] Battegazzore D., Bocchini S., Frache A.: Crystallization kinetics of poly(lactic acid)-talc composites. Express Polymer Letters, 5, 849-858 (2011).

DOI: $10.3144 /$ expresspolymlett.2011.84

[9] Murariu M., Da Silva Ferreira A., Degée P., Alexandre M., Dubois P.: Polylactide compositions. Part 1: Effect of filler content and size on mechanical properties of PLA/calcium sulfate composites. Polymer, 48, 26132618 (2007).

DOI: $10.1016 /$ j.polymer.2007.02.067

[10] Sobkowicz M. J., Feaver J. L., Dorgan J. R.: Clean and green bioplastic composites: Comparison of calcium sulfate and carbon nanospheres in polylactide composites. Clean, 36, 706-713 (2008).

DOI: $10.1002 /$ clen.200800076
[11] Tidjani A., Wilkie C. A.: Photo-oxidation of polymeric-inorganic nanocomposites: Chemical, thermal stability and fire retardancy investigations. Polymer Degradation and Stability, 74, 33-37 (2001).

DOI: 10.1016/S0141-3910(01)00061-1

[12] Qin H., Zhao C., Zhang S., Chen G., Yang M.: Photooxidative degradation of polyethylene/montmorillonite nanocomposite. Polymer Degradation and Stability, 81, 497-500 (2003).

DOI: $10.1016 / \mathrm{S} 0141-3910(03) 00136-8$

[13] Mailhot B., Morlat S., Gardette J-L., Boucard S., Duchet J., Gérard J-F.: Photodegradation of polypropylene nanocomposites. Polymer Degradation and Stability, 82, 163-167 (2003).

DOI: $10.1016 / \mathrm{S} 0141-3910(03) 00179-4$

[14] Morlat S., Mailhot B., Gonzalez D., Gardette J-L.: Photo-oxidation of polypropylene/montmorillonite nanocomposites. 1. Influence of nanoclay and compatibilizing agent. Chemistry of Materials, 16, 377-383 (2004).

DOI: $10.1021 / \mathrm{cm} 031079 \mathrm{k}$

[15] Morlat-Thérias S., Mailhot B., Gonzalez D., Gardette J-L.: Photooxidation of polypropylene/montmorillonite nanocomposites. 2. Interactions with antioxidants. Chemistry of Materials, 17, 1072-1078 (2005). DOI: $10.1021 / \mathrm{cm} 0401721$

[16] Morlat-Thérias S., Mailhot B., Gardette J-L., Da Silva C., Haidar B., Vidal A.: Photooxidation of ethylenepropylene-diene/montmorillonite nanocomposites. Polymer Degradation and Stability 90, 78-85 (2005). DOI: 10.1016/j.polymdegradstab.2005.01.040

[17] Bocchini S., Morlat-Thérias S., Gardette J-L., Camino G.: Influence of nanodispersed boehmite on polypropylene photooxidation. Polymer Degradation and Stability, 92, 1847-1856 (2007).

DOI: $10.1016 /$ j.polymdegradstab.2007.07.002

[18] Bocchini S., Morlat-Thérias S., Gardette J. L., Camino G.: Influence of nanodispersed hydrotalcite on polypropylene photooxidation. European Polymer Journal, 44, 3473-3481 (2008). DOI: $10.1016 /$ j.eurpolymj.2008.08.035

[19] Bocchini S., Fukushima K., Di Blasio A., Fina A., Frache A., Geobaldo F.: Polylactic acid and polylactic acid-based nanocomposite photooxidation. Biomacromolecules, 11, 2919-2926 (2010). DOI: $10.1021 / \mathrm{bm} 1006773$

[20] Gardette M., Thérias S., Gardette J-L., Murariu M., Dubois P.: Photooxidation of polylactide/calcium sulphate composites. Polymer Degradation and Stability, 96, 616-623 (2011). DOI: $10.1016 /$ j.polymdegradstab.2010.12.023

[21] Li H., Huneault M. A.: Effect of nucleation and plasticization on the crystallization of poly(lactic acid). Polymer, 48, 6855-6866 (2007).

DOI: $10.1016 /$ j.polymer.2007.09.020 
[22] Leong Y. W., Abu Bakar M. B., Mohd Ishak Z. A., Ariffin A.: Characterization of talc/calcium carbonate filled polypropylene hybrid composites weathered in a natural environment. Polymer Degradation and Stability, 83, 411-422 (2004).

DOI: $10.1016 /$ j.polymdegradstab.2003.08.004

[23] Rotzinger B.: Talc-filled PP: A new concept to maintain long term heat stability. Polymer Degradation and Stability, 91, 2884-2887 (2006).

DOI: $10.1016 /$ j.polymdegradstab.2006.09.008

[24] Utracki L. A., Broughton B., González-Rojano N., de Carvalho L. H., Achete C. A.: Clays for polymeric nanocomposites. Polymer Engineering and Science, 51, 559-572 (2011).

DOI: 10.1002/pen.21807

[25] Philippart J-L., Sinturel C., Gardette J-L.: Influence of light intensity on the photooxidation of polypropylene. Polymer Degradation and Stability, 58, 261-268 (1997). DOI: 10.1016/S0141-3910(97)00056-6

[26] Wei P., Bocchini S., Camino G.: Nanocomposites combustion peculiarities. A case history: Polylactideclays. European Polymer Journal, in press (2013).

DOI: 10.1016/j.eurpolymj.2012.11.010

[27] Fukushima K., Murariu M., Camino G., Dubois P.: Effect of expanded graphite/layered-silicate clay on thermal, mechanical and fire retardant properties of poly(lactic acid). Polymer Degradation and Stability, 95, 1063-1076 (2010).

DOI: $10.1016 /$ j.polymdegradstab.2010.02.029

[28] Fukushima K., Fina A., Geobaldo F., Venturello A., Camino G.: Properties of poly(lactic acid) nanocomposites based on montmorillonite, sepiolite and zirconium phosphonate. Express Polymer Letters, 6, 914 926 (2012).

DOI: $10.3144 /$ expresspolymlett.2012.97

[29] Pluta M., Galeski A., Alexandre M., Paul M-A., Dubois P.: Polylactide/montmorillonite nanocomposites and microcomposites prepared by melt blending: Structure and some physical properties. Journal of Applied Polymer Science, 86, 1497-1506 (2002). DOI: 10.1002/app.11309

[30] Rayner J. H., Brown G.: The crystal structure of talc. Clays and Clay Minerals, 21, 103-114 (1973). DOI: $10.1346 / C C M N .1973 .0210206$
[31] Xiao H. W., Li P., Ren X., Jiang T., Yeh J-T.: Isothermal crystallization kinetics and crystal structure of poly(lactic acid): Effect of triphenyl phosphate and talc. Journal of Applied Polymer Science, 118, 35583569 (2010). DOI: $10.1002 / a p p .32728$

[32] Karickhoff S. W., Baley G. W.: Optical absorption spectra of clay minerals. Clays and Clay Minerals, 21, 59-70 (1973).

DOI: $10.1346 / C C M N .1973 .0210109$

[33] Strawhecker K. E., Manias E.: Structure and properties of poly(vinyl alcohol) $/ \mathrm{Na}^{+}$montmorillonite nanocomposites. Chemistry of Materials, 12, 2943-2949 (2000). DOI: $10.1021 / \mathrm{cm} 000506 \mathrm{~g}$

[34] Ray S. S., Okamoto M.: Polymer/layered silicate nanocomposites: A review from preparation to processing. Progress in Polymer Science, 28, 1539-1641 (2003).

DOI: $10.1016 /$ j.progpolymsci.2003.08.002

[35] Kister G., Cassanas G., Vert M.: Effects of morphology, conformation and configuration on the IR and Raman spectra of various poly(lactic acid)s. Polymer, 39, 267-273 (1998).

DOI: $10.1016 / \mathrm{S} 0032-3861(97) 00229-2$

[36] Vantelon D., Pelletier M., Michot L. J., Barres O., Thomas F.: Fe, Mg and $\mathrm{Al}$ distribution in the octahedral sheet of montmorillonites. An infrared study in the $\mathrm{OH}-$ bending region. Clay Minerals, 36, 369-379 (2001).

[37] Schroeder P. A.: Infrared spectroscopy in clay science. CMS Workshop Lectures, 11, 181-206 (2002).

[38] Krikorian V., Pochan D. J.: Crystallization behavior of poly(L-lactic acid) nanocomposites: Nucleation and growth probed by infrared spectroscopy. Macromolecules, 38, 6520-6527 (2005). DOI: $10.1021 / \mathrm{ma} 050739 \mathrm{z}$

[39] Mayo D. W.: Spectra of carbonyl compounds of all kinds (factors affecting carbonyl group frequencies). in 'Course notes on the interpretation of infrared and raman spectra' (eds.: Mayo D. W., Miller F. A., Hannah R. W.) Wiley, New York, 179-204 (2003).

[40] Rånby B., Rabek J. F.: Photodegradation photo-oxidation and photostabilisation of polymers. Wiley, London (1975).

[41] Okamoto K., Toshima K., Matsumura S.: Degradation of poly(lactic acid) into repolymerizable oligomer using montmorillonite K10 for chemical recycling. Macromolecular Bioscience, 5, 813-820 (2005). DOI: $\underline{10.1002 / \mathrm{mabi} .200500086}$ 